\title{
Fibroma and giant-cell tumor of tendon sheath: a case report
}

This article was published in the following Dove Press journal:

Orthopedic Research and Reviews

3 April 2014

Number of times this article has been viewed

\author{
Kátia Tôrres Batista' \\ Heveline Becker de Moura' \\ Maria Isabel Lima ${ }^{2}$ \\ Kikue Terada $\mathrm{Abe}^{3}$ \\ 'Department of Plastic Surgery and \\ Pathology, ${ }^{2}$ Electron Microscopy \\ Laboratory, ${ }^{3}$ Cytogenetic Laboratory, \\ Sarah Hospital Brasilia, Brazil
}

\begin{abstract}
A 53-year-old man presented in 2009 with a tumor over the dorsum of his hand and wrist. Magnetic resonance imaging was performed before surgery and histopathological and immunohistochemical studies were performed after surgery. This demonstrated an ill-defined lesion measuring $46 \mathrm{~mm} \times 31 \mathrm{~mm}$ confined to the subcutaneous tissues, extensor tendons, and articular capsule on the dorsum of the hand and wrist with heterogeneous intermediate and high T1 and T2 signal suggesting a complex mixture of fat and fibrous elements. A histopathological differential diagnosis of hemosiderotic fibrohistiocytic lipomatous lesion/tumor (HFLL/T) and giant-cell tumor of tendon sheath and fibroma of tendon sheath was made. We describe this rare lesion and call attention to important points in diagnosis.
\end{abstract}

Keywords: giant cell tumor, fibroma tumor, sheath tendon tumor

\section{Introduction}

Fibroma and giant-cell tumor (GCT) of the tendon sheath are lesions that occur typically in the extremities and belong to a heterogeneous group of fibrohistiocytic lesions. These lesions present similar clinical and histological features; however, researchers describe different views on the origin of these two entities. According to some authors, they may correspond to different stages of the same pathologic process, ${ }^{1-5}$ and others suggest that the fibroma and GCT are distinct tumors. We describe a patient presenting a benign fibrohistiocytic hemosiderotic lesion that demonstrated transitional morphological characteristics between the GCT and fibroma of the tendon sheath.

\section{Case report}

A 53-year-old male presented a slow-growing lesion on the dorsum of the hand and wrist for about 1 year, resulting in difficult wrist motion and pain. The patient did not have antecedent of trauma or vascular insufficiency. Laboratory test results (complete blood count, glucose, erythrocyte sedimentation rate, polymerase chain reaction, latex, thyroid stimulating hormone, uric acid, antinuclear antibody, urea, and creatinine) were normal. The diagnosis of hemochromatosis was ruled out based on the criteria of the American Association for the Study of Liver Diseases. On physical examination, it was a bulky tumor in the dorsum of the hand and wrist, measuring approximately $4 \mathrm{~cm}$ in greatest diameter. The extension of the wrist was limited to $40^{\circ}$ range of motion. There were no muscle weakness or sensibility changes. The hand function was preserved. The patient underwent an MRI (magnetic resonance imaging) scan (Figure 1A and B), and subsequent excision of the tumor was carried out.
Correspondence: Kátia Tôrres Batista Plastic Surgery Department, Sarah Hospital, SMHS Qd 50I

Conjunto A - CEP 70335-901, Brasilia, Brasil

Email katiatb@terra.com.br 

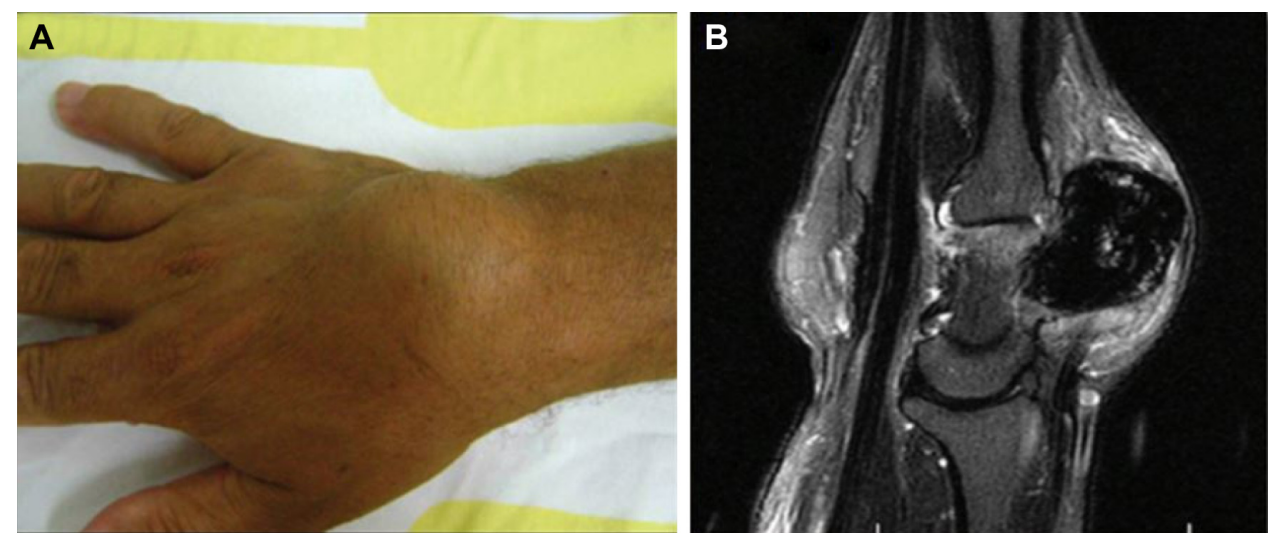

Figure I (A) Preoperative; (B) Magnetic resonance imaging revealed a well defined, expanding lesion with a predominance of low signal, suggesting hemosiderin deposits or other ferromagnetic material, with expansive and infiltrative component. The tumor had an epicenter in the dorsal carpal tendons between the fourth and second compartment extenders.

The surgical procedure was performed under brachial plexus block anesthesia with tourniquet of upper limb. Zigzag incision in the dorsum of the hand identified a tumor nodule measuring approximately $3.5 \mathrm{~cm}$, located under the extensor tendons (Figure 2). The tumor was hypervascular, presented lobulated borders with areas similar to fat, and darkened areas with fibrin deposits. There was no cleavage plane in depth. Frozen section showed a benign spindle cell neoplasm with hemosiderin pigments. On gross examination, the tumor measured $3.5 \mathrm{~cm} \times 2.3 \mathrm{~cm} \times 1.9 \mathrm{~cm}$ and weighed $16.5 \mathrm{~g}$. It was a well defined nodular tumor presenting a brownish coloration with yellow areas and was partially covered by a capsule and adipose tissue (Figure 3).

The sections stained with hematoxylin and eosin showed a benign lesion of soft tissue showing nodular areas permeated by adipose tissue at the periphery. It was composed of polygonal cells, spindle cells, and macrophages. The polygonal cells were distributed in groups near the vessels. The stroma was collagenized and hyalinized, well vascularized, with foci of mature adipose tissue within the tumor. It had a large amount of hemosiderin deposits that were evidentiated by Perls' stain. These hemosiderin deposits were mostly within the cytoplasm of macrophages, but were also found in the cytoplasm of vessel smooth muscle cells, endothelial cells, and fibroblasts. We did not observe giant cells, myxoid areas, or extravasation of red blood cells in the histological sections (Figures 4-6). The spindle and polygonal cells expressed smooth muscle actin, vimentin and a dubious reactivity for $\mathrm{CD} 34$ in an immunohistochemical study. The presence of large amounts of hemosiderin made difficult the interpretation of the antibody CD34 that was expressed in coarse granules within the cytoplasm of spindle cells, macrophages, and fibroblasts. We repeated the CD34 several times, but the hemosiderin interfered, and it was not possible to depigment; unfortunately we did not have immunofluorescence. So, the CD34 was considered negative. Spindle and polygonal cells were negative for P75GFR, CD31, CD45, HHF35, S100 protein, and CD68. Macrophages express CD68 and alpha 1 antichymotrypsin. We performed the CD68 (KP10) because it is more specific than HAM56 for macrophages. The response was strong and focal. We believed it would not help to define the diagnostic; the
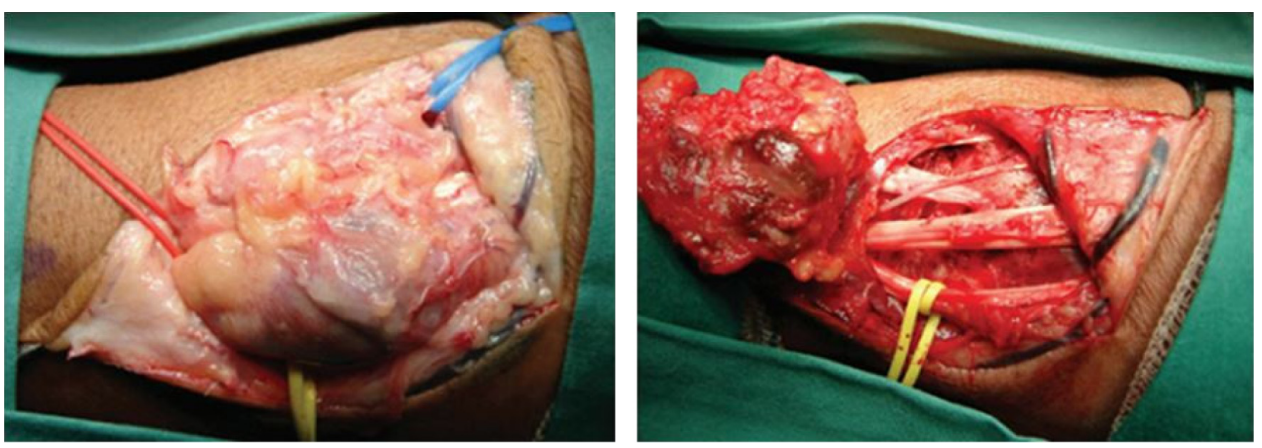

Figure 2 Intraoperative. 


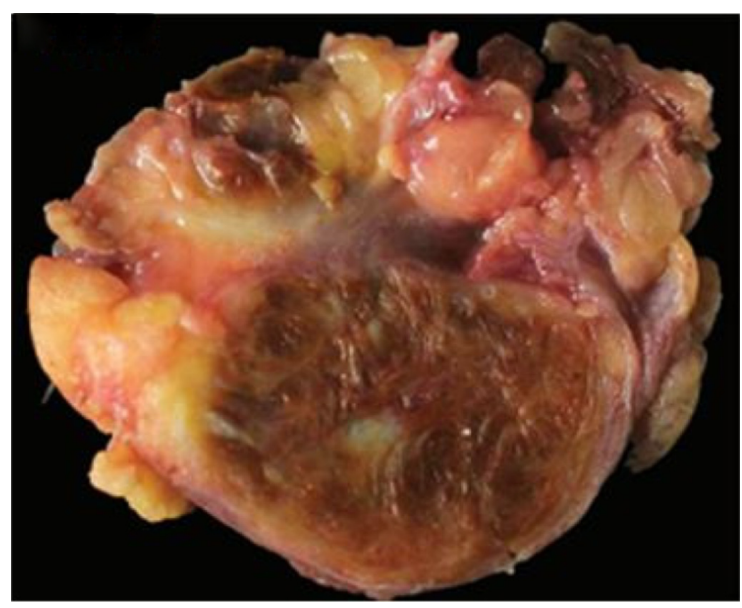

Figure 3 Macroscopy.

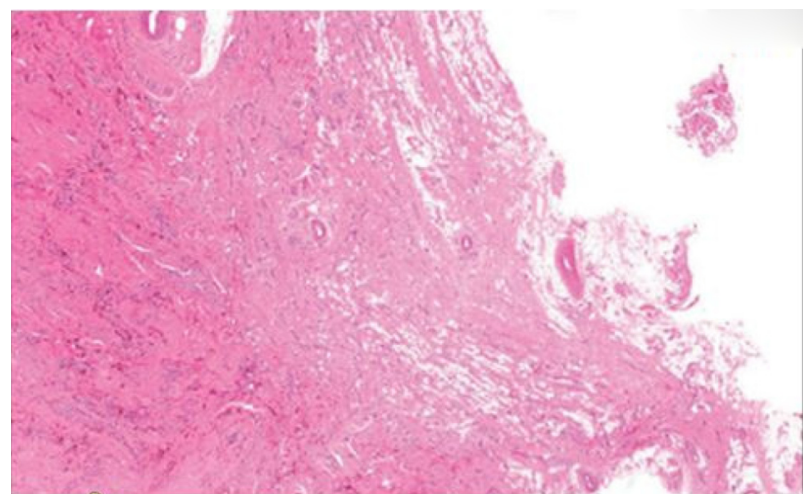

Figure 5 Microscopy.

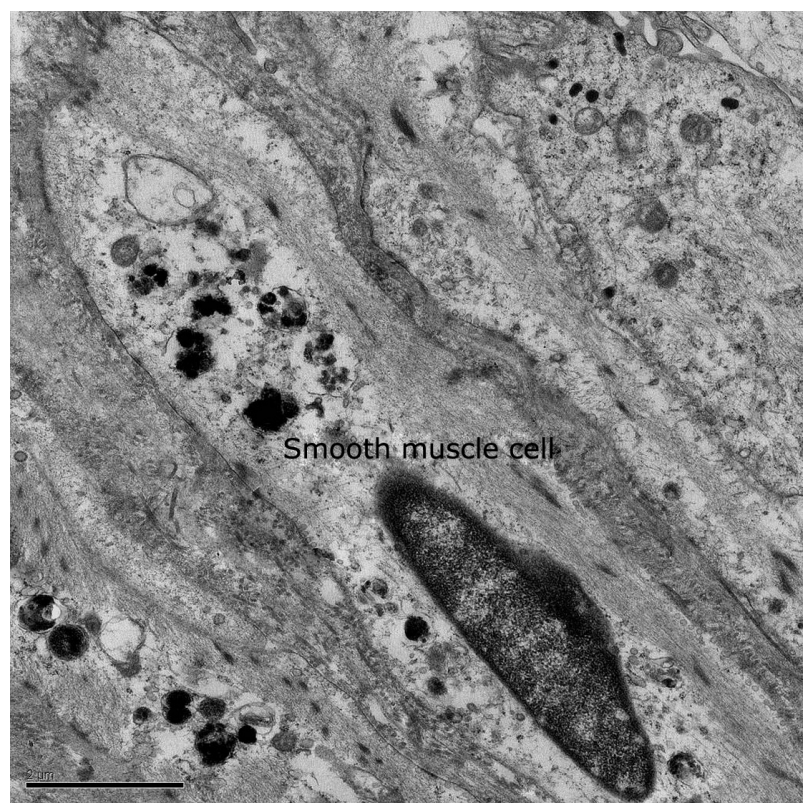

Figure 7 Smooth muscle cells in electron microscopy.

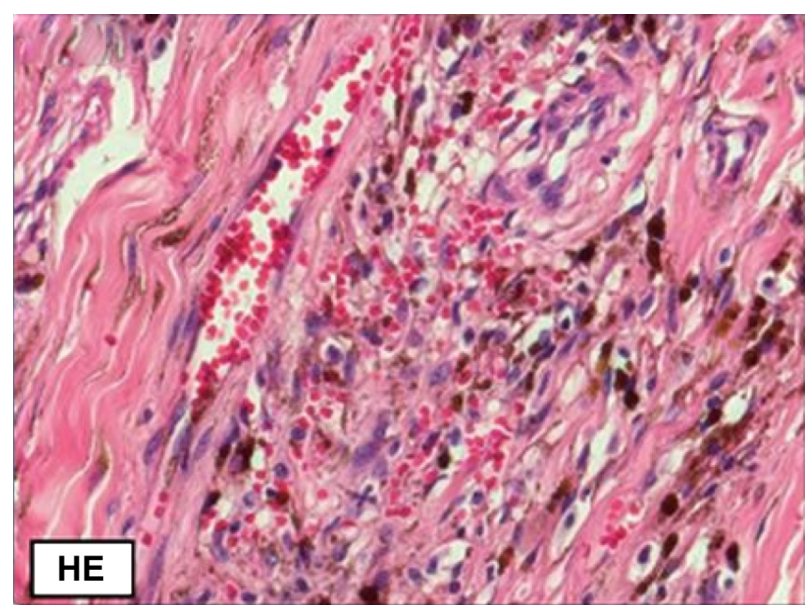

Figure 4 Microscopy-the sections stained with hematoxylin and eosin (HE).

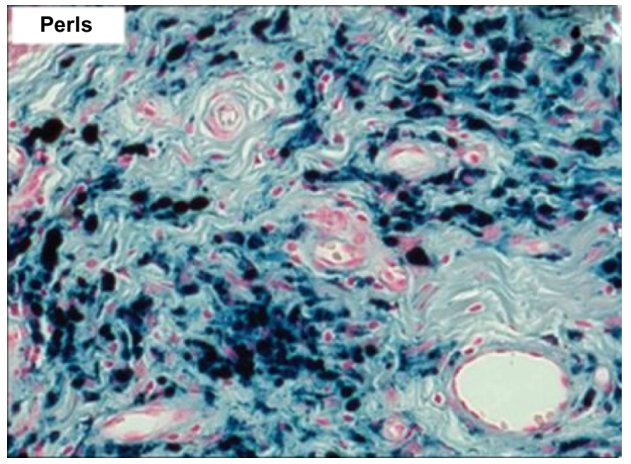

Figure 6 A large amount of hemosiderin deposits that were evidentiated by Pearls Stain.

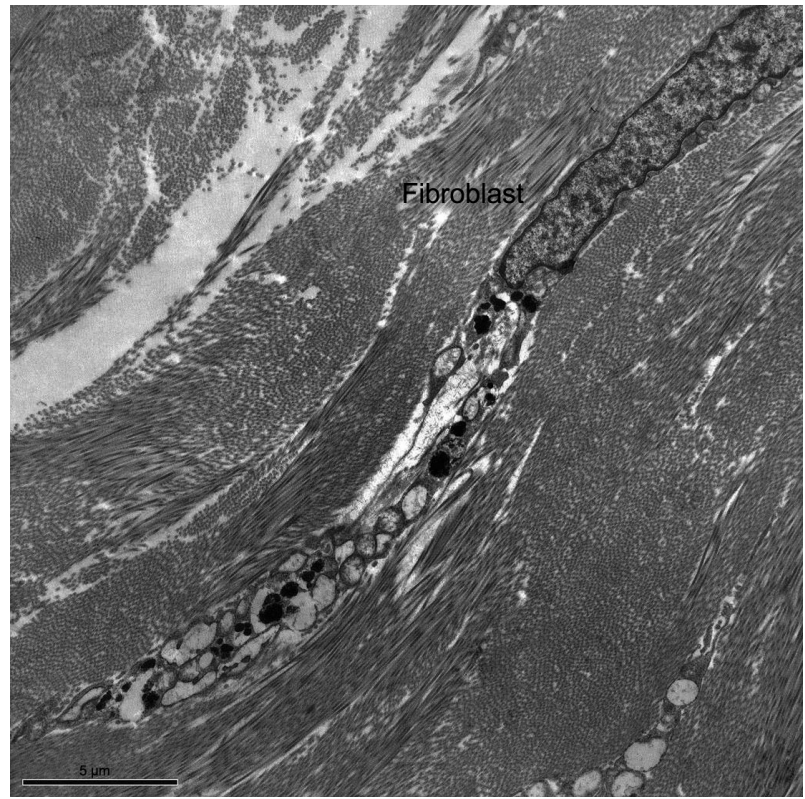

Figure 8 Fibroblasts were observed in electron microscopy. 
Table I Antibodies used in this study

\begin{tabular}{lll}
\hline Antibody (clone) & Commercial source & Dilution \\
\hline CD68 & Dako & $\mathrm{I}: 2,000$ \\
Vimentin (V9) & Dako & $\mathrm{I}: 4,000$ \\
SI00 protein & Dako & $\mathrm{I}: 5,000$ \\
Muscle-specific actin (HHF35) & Dako & $\mathrm{I}: \mathrm{I}, 000$ \\
CD34 (Qend/I0) & Novocastra & $\mathrm{I}: 400$ \\
CD3I (JC70A) & Dako & $\mathrm{I}: 300$ \\
CD45 (2BII + PD7/26) & Dako & $\mathrm{I}: 2,500$ \\
P75 (NGFR 5) & Dako & $\mathrm{I}: 200$ \\
$\alpha$-smooth muscle actin (IA4) & Dako & $\mathrm{I}: \mathrm{I}, 000$ \\
$\alpha$-I-antichymotrypsin & Dako & $\mathrm{I}: 700$ \\
\hline
\end{tabular}

morphology was more important. The antibodies with their dilutions are shown in Table 1. Negative and positive controls were used in this study. The electron microscopy examination revealed a large amount of connective tissue (collagen fibers) permeated by blood vessels, fibroblasts, macrophages, and mast cells. Numerous vesicles filled with a material consistent with hemosiderin in the cytoplasm of smooth muscle cells (Figure 7), endothelial cells, fibroblasts, (Figure 8), and macrophages were observed. Cytogenetic results demonstrated clonal chromosome aberrations as trisomy 8 and translocation $\mathrm{t}(5 ; 7)(\mathrm{p} 12 ; \mathrm{q} 36)$. Based on clinical, histopathological, ultrastructural, and immunohistochemical features (Figure 9), a diagnosis of a benign fibrohistiocytic lesion was made. The three major differential diagnoses of this lesion were hemosiderotic fibrohistiocytic lipomatous tumor, CGT of the tendon sheath, and fibroma of tendon sheath, but other diagnostic differentials needed to be ruled out.

The patient's pain improved and the functional pattern of the hand remained the same after 1 year postoperative follow up. There was no recurrence.

\section{Discussion}

The GCT and fibroma are benign fibrohistiocytic lesions of the tendon sheath. These lesions share similar clinical features such as site, multinodular, attachment to the tendon, and the recurrence rate. However, they differ histologically, except for a variant degree of collagen formation and hyalinization present in both lesions. Based on these observations, the possible overlap between these lesions has been reported by some authors. ${ }^{2,5}$ Satti $^{2}$ suggested that fibroma is probably one end of the morphological spectrum of regression of GCT of tendon sheath, evidenced by the hyalinization characteristic of the former. To support his hypothesis, Satti described a transitional stage between that of two lesions, probably consequent on progressive vascular impairment. ${ }^{2}$ Maluf et $\mathrm{al}^{5}$ described that there is no sufficient criteria to separation of GCT and fibroma of the tendon sheath as distinct pathological entities. However, other authors have hypothesized that the two lesions are unrelated and represented two distinct clinical entities. ${ }^{6}$

In the present study, we have a slow-growing lesion of the tendon sheath where the clinical and radiological characteristics were nondiscriminatory for a definitive diagnosis between GCT and fibroma. The gross study showed a brown nodular lesion that resembled GCT of the tendon sheath. On light microscopy study, all cells of the lesion had hemosiderin pigments within their cytoplasm, and no multinucleated giant cells were seen. The presence of hemosiderin is rare in fibroma, but Smith et $\mathrm{al}^{7}$ related fibroma with siderophages. The absence of multinucleated giant cell did not help in the differential diagnosis between GCT and fibroma of tendon sheath. The GCT can show none or a variable number of multinucleated giant cells. The presence of these cells is rare in fibroma, but not impossible. The

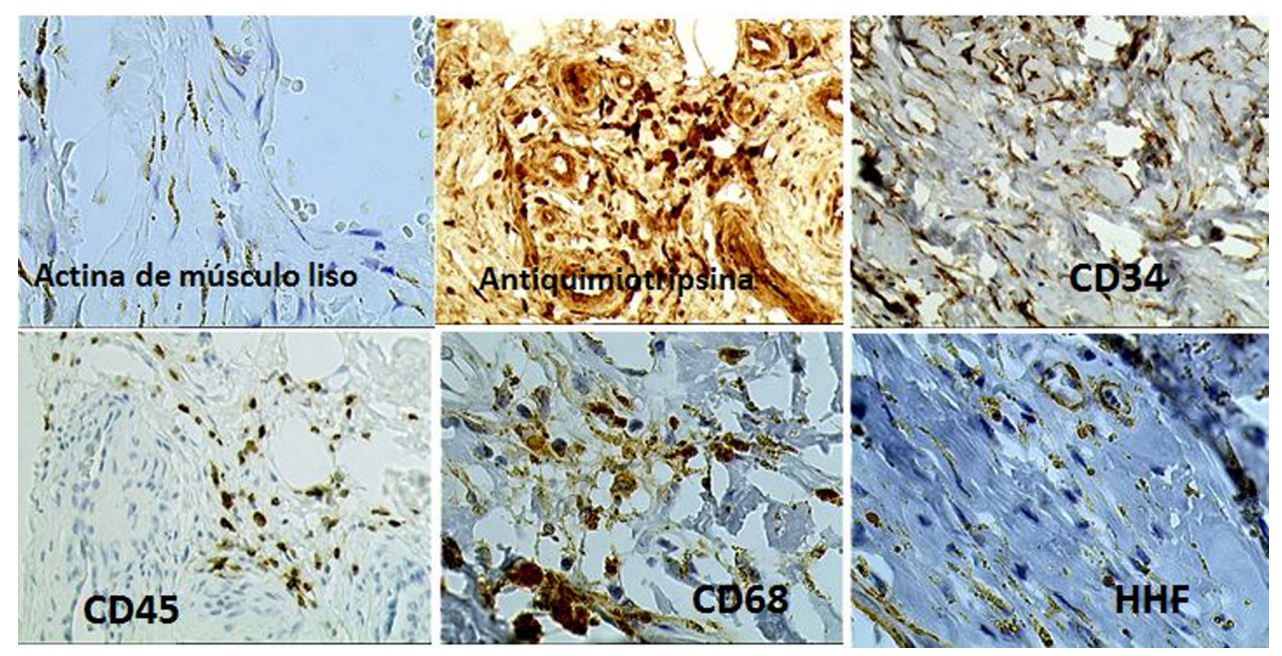

Figure 9 Immunohistochemical studies positive. 
results of the immunohistochemistry study were interpreted as representing a mixture of histiocytic and myofibroblastic differentiation, and these dates were confirmed by electron microscopy. A number of others tumors enter the differential diagnosis, nodular fasciitis, desmoid tumor/fibromatosis and benign fibrous histiocytoma. Nodular fasciitis typically grows rapidly and has a predilection for the subcutaneous tissues of the upper extremities. ${ }^{8}$ Desmoid tumor/fibromatosis are locally aggressive tumors that occur in the abdominal wall, mesentery, and in extra-abdominal deep soft tissues, and show infiltrative margins. They are characterized by long, sweeping fascicles and often contain relatively large blood vessels. Some cases of desmoid fibromatosis show prominent myxoid stroma. ${ }^{8}$ Lack of these histological features ruled out diagnosis of a desmoid tumor/fibromatosis. The histological features of the present lesion tended to exclude the diagnosis of fibromatosis. ${ }^{7}$ Three other important differential diagnoses to exclude, because of the presence of mature adipocytes and a possible expression of CD34 in some stromal cells, were hemosiderotic fibrohistiocytic lipomatous lesion/tumor (HFLL/T), spindle cell lipoma, and solitary fibrous tumor. So-called HFHL/T is a rare and unusual lesion occurring mainly in the distal extremities and characterized by a grossly lipomatous lesion, which is microscopically composed of three elements occurring in varying proportions: mature adipocytes, spindle cells, and hemosiderin pigment. HFHL/T is positive for CD34 and negative for SMA, desmin, CD68, and $\mathrm{S}-100 .{ }^{4}$ The hemosiderin pigment is present predominantly in macrophages. ${ }^{4}$ We found, on electron microscopy study, hemosiderin within the cytoplasm of smooth muscle cells, endothelial cells, fibroblasts, and macrophages. We ruled out this diagnosis, because grossly, our lesion was not compatible with HFLL/T, and the immunohistochemical study showed features not observed in this tumor (positivity for SMA and negativity for CD34). Spindle cell lipoma and solitary fibrous tumor were discarded on the basis of the lack of histologically specific features and negativity for CD34.

Cytogenetic results demonstrated clonal chromosome aberrations as trisomy 8 and $\mathrm{t}(5 ; 7)$ translocation. These chromosome alterations have not been described in GCT or in fibromas before. There is no cytogenetic study about HFLL/T in the literature. Trisomy 8 has been reported as clonal aberration in Dupuytren's contracture, plantar fibromatosis, Peyronie's disease, infantile fibrosarcoma, solitary fibrous tumor, and desmoid tumors. ${ }^{9}$ However, this lesion does not present clinical or histological features compatible with tumors that have the trisomy 8 , which were cited earlier.
The translocation $\mathrm{t}(5 ; 7)$ was not specific for any soft tissue tumor. This translocation was identified in rhabdomyosarcoma, embryonal rhabdomyosarcoma, malignant peripheral nerve sheath tumor, and malignant fibrous histiocytoma. ${ }^{9,10}$ All of these are malignant, and the lesion studied presents histological benign features. The cytogenetic examination did not help in the differential diagnosis between GCT and fibroma. Histology and electron microscopy allowed us to discard some differential diagnoses but did not help in achieving a definitive diagnosis. Based on these observations, the overlap between these lesions that has been reported by some authors may be possible., ${ }^{2,5}$

\section{Conclusion}

We described a hemosiderotic fibrohistiocytic benign lesion that had no sufficient radiological, clinical, morphological, and cytogenetic criteria to separate GCT and fibroma of tendon sheath and had no specific characteristic for a definitive diagnosis. This lesion, according to $\mathrm{Satti}^{2}$ and Maluf et al, ${ }^{5}$ may represent the extremes in a spectrum of a histiocytic and myofibroblastic proliferation, or we may be faced with a new fibrotic lesion. Further investigation is required into the spectrum of these fibrous lesions.

\section{Disclosure}

The authors report no conflicts of interest in this work.

\section{References}

1. Marshall-Taylor C, Fanburg-Smith JC. Hemosiderotic fibrohistiocytic lipomatous lesion: ten cases of a previously undescribed fatty lesion of the foot/ankle. Mod Pathol. 2000;13(11):1192-1199.

2. Satti MB. Tendon sheath tumours: a pathological study of the relationship between giant cell tumour and fibroma of tendon sheath. Histopathology. 1992;20(3):213-220.

3. West AT, Tomas AP, Murphy J, Sultan M. Haemosiderotic fibrohistiocytic lipomatous lesion/tumour of the foot. MRI and histopathology. Skeletal Radiol. 2008;37(1):71-74.

4. Browne TJ, Fletcher CD. Haemosiderotic fibrolipomatous tumour (so-called haemosiderotic fibrohistiocytic lipomatous tumour): analysis of 13 new cases in support of a distinct entity. Histopathology. 2006;48: 453-461.

5. Maluf HM, DeYoung BR, Swanson PE, Wick MR. Fibroma and giant cell tumor of tendon sheath: a comparative histological and immunohistological study. Mod Pathol. 1995;8(2):155-159.

6. Pulitzer DR, Martin PC, Reed RJ. Fibroma of tendon sheath: a clinicopathologic study of 32 cases. Am J Surg Pathol. 1989;13:472-479.

7. Smith PS, Pieterse AS, McClure J. Fibroma of tendon sheath. J Clin Pathol. 1982;35:842-848.

8. Bridge JA, Swarts SJ, Buresh C, et al. Trisomies 8 and 20 characterize a subgroup of benign fibrous lesions arising in both soft tissue and bone. Am J Pathol. 1999;154(3):729-733.

9. Becher R, Wake N, Gibas Z, Ochi H, Sandberg AA. Chromosome changes in soft tissue sarcomas. J Natl Cancer Inst. 1984;72:823-831.

10. Gordon T, McManus A, Anderson J, et al. Cytogenetic abnormalities in 42 rhabdomyosarcoma: a United Kingdom Cancer Cytogenetics Group Study. Med Pediatr Oncol. 2001;36(2):259-267. 
Orthopedic Research and Reviews

Dovepress

\section{Publish your work in this journal}

Orthopedic Research and Reviews is an international, peer-reviewed, open access journal focusing on the patho-physiology of the musculoskeletal system, trauma, surgery and other corrective interventions to restore mobility and function. Advances in new technologies, materials, techniques and pharmacological agents are particularly welcome. The journal welcomes

original research, clinical studies, reviews \& evaluations, expert opinion and commentary, case reports and extended reports. The manuscript management system is completely online and includes a very quick and fair peer-review system, which is all easy to use. Visit http://www.dovepress. com/testimonials.php to read real quotes from published authors.

Submit your manuscript here: http://www.dovepress.com/orthopedic-research-and-reviews-journal 